\title{
Purification and function analysis of the $\Delta-17$ fatty acid desaturase with or without transmembrane domain
}

\author{
HAOYU ZHOU and CHENGMING WANG
}

Department of Food Science and Technology, Huazhong Agricultural University, Wuhan, Hubei 430000, P.R. China

Received August 16, 2016; Accepted April 11, 2017

DOI: $10.3892 /$ etm. 2017.4790

\begin{abstract}
Fatty acid desaturation enzymes perform dehydrogenation reactions leading to the insertion of double bonds in fatty acids. $\omega-3$ desaturase has an important role in converting $\omega-6$ fatty acids into $\omega-3$ fatty acids. Although genes for this desaturase have been identified, the enzymatic activity of $\Delta-17$ with or without transmembrane domain, and the function of the $\Delta-17$ desaturase is poorly understood. In the present study, a transgenic microorganism was used to clone the $\Delta-17$ full length $(\Delta-17 \mathrm{FL})$ and $\Delta-17$ without transmembrane domain $(\Delta-17 \mathrm{NT})$, the expression efficiency was improved and western blotting was used to detect the protein expression level. The purification of $\Delta-17$ was precipitated using saturated ammonium sulfate solution, dissolved in phosphate buffered saline buffer, and then filtered using a $10 \mathrm{kDa}$ ultrafiltration cube. Gas chromatography analysis was used to measure the effect of $\Delta-17 \mathrm{NT}$ or $\Delta-17 \mathrm{FL}$ expression on Pichia pastoris fatty acid composition. Furthermore, the function of $\Delta-17 \mathrm{NT}$ in HepG2 cells was measured and the mechanism was explored. It was demonstrated that $\Delta-17 \mathrm{NT}$ decreased cell growth and increased apoptosis in hepatocellular carcinoma cell lines in vitro. In conclusion, successful expression of high levels of recombinant $\Delta-17 \mathrm{NT}$ represents a critical step towards the elucidation of the function of membrane fatty acid desaturases.
\end{abstract}

\section{Introduction}

It is understood that mammals lack $\Delta-12, \Delta-15$ and $\Delta-17$ fatty acid desaturases, thus are unable to synthesize $\omega-6$ and -3 fatty acids (1). The homeostasis stability of $\omega-6$ and -3 polyunsaturated fatty acid has an important role in the normal growth and development of the body environment $(2,3)$. Fatty acid desaturase enzymes may be divided into soluble enzymes and membrane-bound enzymes (4). Although some progress has

Correspondence to: Professor Chengming Wang, Department of Food Science and Technology, Huazhong Agricultural University, 1 Shizi Shan Street, Wuhan, Hubei 430000, P.R. China

E-mail: chengmingwang999@sina.com

Key words: $\Delta-17$ fatty acid desaturase, purification, function analysis, transmembrane domain been made on the study of desaturases, due to the technical constraints of membrane protein extraction and crystallization, the knowledge about the structure and expression regulation of membrane-bound fatty acid desaturases is still lacking $(5,6)$, and whether the transmembrane domain has a role in fatty acid desaturase efficiency remains unknown.

Using transgenic technology to effectively express saturated fatty acid desaturase genes in lower eukaryotes, $\omega-6$ polyunsaturated fatty acids may be catalyzed into the corresponding $\omega-3$ polyunsaturated fatty acids (7). To obtain a highly expressed and purified membrane-bound fatty acid and verify its activity is the first step for understanding the structure and function of the desaturase (8). The production of some new, high-value fatty acids may better control enzyme activity and substrate specificity, and provide important scientific insight $(9,10)$.

In the present study, $\Delta-17$ fatty acid desaturase was optimized and the transmembrane of $\Delta-17$ fatty acid desaturase was removed. A yeast eukaryotic expression vector was constructed and, to improve the expression efficiency and compare the enzymatic activity, western blotting was utilized to detect protein expression levels. Through optimization of the $\omega-3$ desaturase gene, it is able to convert $\omega-6$ polyunsaturated fatty acids to $\omega-3$ polyunsaturated fatty acids in mammalian cells (11). The discovery of the underlying mechanism and function of $\Delta-17$ fatty acid desaturase with or without transmembrane domain in HepG2 cells may contribute to the understanding of the fatty acid desaturase.

\section{Materials and methods}

Clone of $\Delta-17$ fatty acid desaturase recombinant plasmid. The original sequence of $\Delta-17$ of Phytophthora ramorum was obtained from the National Center for Biotechnology information (FW362214.1; https://www.ncbi.nlm.nih.gov) MaxCodon TM Optimization Program v. 13.0 (Detai Biologics co., Ltd., Nanjing, China) was used to optimize the code of $\Delta$-17FAD. The expression vector, pPICZ $\alpha$ A, was purchased from Invitrogen (Thermo Fisher Scientific, Inc., Waltham, MA, USA). The above plasmid was amplified in DH5a bacteria (Promega Corporation, Madison, WI, USA) in Luria Bertani medium (Tryptone $10 \mathrm{~g} / \mathrm{l}$, Yeast extract $5 \mathrm{~g} / 1$ and $\mathrm{NaCl} 10 \mathrm{~g} / \mathrm{l}$; Sigma-Aldrich; Merck KGaA, Darmstadt, Germany) supplemented with $100 \mu \mathrm{g} / \mu \mathrm{l}$ ampicillin at $37^{\circ} \mathrm{C}$. After shaking at $250 \mathrm{rpm}$ for $16 \mathrm{~h}$, the plasmid was purified using a Qiagen Maxi 
kit (Qiagen, Inc., Valencia, CA, USA), according to the manufacturer's instructions. The optimized sequence of the $\Delta-17$ was as follows: 1 ATGGCTACCAAGCAACCTTATCAGTTCCC TACTTTGACCGAGATTAAGAGATCCCTTCCT; 61 TCA GAATGTTTTGAGGCATCAGTCCCATTGTCTCTTTACT ATACAGTTAGAATTGTCGCA; 121 ATCGCTGTTGCCC TTGCATTTGGATTGAACTATGCTAGAGCCTTGCCAGT TGTCGAATCC; 181 CTTTGGGCTTTGGATGCTGCCTT GTGTTGCGGTTACGTTTTGCTTCAAGGTATTGTCTTT; 241 TGGGGATTTTTCACTGTTGG TCACGACGCAGG TCATGGAGCTTTCTCAAGATACCACTTG; 301 CTT AACTTCGTTGTCGGAACCTTCATTCATTCATTGATCC TTACTCCTTTTGAAAGTTGG; 361 AAGTTGACACACA GACATCACCATAAAAACACCGGTAATATTGATAGAG ACGAGATCTTC; 421 TATCCACAGAGAAAGGCTGATGA CCATCCTTTGTCTAGAA ACTTGGTTCTTGCCTT GGGA; 481 GCAGCTTGGT TTGCATACTTGGTTGAAGG TTTCCCACCTAGAAAAGTTAACCACTTTAAT; 541 CCA TTCGAGCCTTTGTTTGT TAGACAAGTCGCCGCAGT TGTCATTTCATTGAGTGCACAT; 601 TTCGCTG TTCTTGCCTTGTCTGTCTACTTGTCCTTTCAGTTCGG TCTTAAGACTATGGCT; 661 TTGTACTATTACGGAC CAGTTTTTGTCTTCGGTTCAATGCTTGTTATTACTAC ATTTTTG; 721 CACCATAACGATGAAGAGACTCCTTG GTATGGAGATAGTG ACTGGACATACGTTAAGGGT; 781 AATTTGTCTT CCGTCGATAG ATCTTATGGAGC TTTTATCGACAACTTGTC CCACAATATT; 841 GGTACC CATCAAATCCACCATCTTTTCCCAATTATCССТCACT ACAAATTGAACAGAGCT; 901 ACTGCTGCCTTTCATC AGGCCTTCCCAGAACTTGTTAGAAAGTCCGATGAGC CTATTTTG; 961 AAAGCATTCTGGAGAGTTGGAAG ACTTTATGCTAATTACGGTGTTGTCGATCCAGACGCC; 1021 AAATTGTTTACATTGAAAGAAGCAAAGGCAGC ATCCGAGG CAGCCACCAA GACTAAGGCA'; 1081 ACC.

The prediction of $\Delta-17(\omega-3)$ fatty acid desaturase transmembrane domain was performed using the TMHMM server, version 2.0 (http://www.cbs.dtu.dk/services/TMHMM/). The $\Delta-17$ desaturase full length $(\Delta-17 \mathrm{FL})$ and $\Delta-17$ without transmembrane domain $(\Delta-17 \mathrm{NT})$ were synthesized from genomic DNA and mixed with the potential restriction digestion position XhoI and NotI (Takara Bio, Inc., Otsu, Japan). The expression vector, pPICZ $\alpha$ A (an affiliate of Promega (Beijing) Biotech Co., Ltd, Beijing, China), was digested with XhoI and NotI. pMD $^{\mathrm{TM}}$ 18-T Vector Cloning kit (Takara Bio, Inc.; catalogue no. 6011) was used to connect pPICZ $\alpha \mathrm{A}$ and $\Delta-17$ (FL) or $\Delta-17$ (NT) to obtain the recombinant plasmid, following the manufacturers protocol. Then the recombinant plasmids, $\Delta-17 \mathrm{NT}$ and $\Delta-17 \mathrm{FL}$, and expression vector, pPICZ $\alpha \mathrm{A}$, were linearized using the restriction enzyme SalI (Takara Bio, Inc.). The reaction system was $50 \mu \mathrm{l}$, including $5 \mu \mathrm{l} 10 \mathrm{xBuffer} \mathrm{H}, 30 \mu \mathrm{l}$ recombinant plasmid pPICZ $\alpha \mathrm{A}-\Delta-17$ (FL) or pPICZ $\alpha \mathrm{A}-\Delta-17$

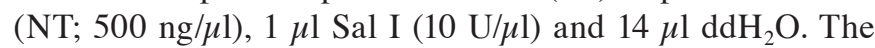
mixture was digested for $3 \mathrm{~h}$ at $37^{\circ} \mathrm{C}$.

Preparation of Pichia pastoris competent cells. Yeast X-33 (Invitrogen; Thermo Fisher Scientific, Inc.) single colonies were picked from YPD plates, inoculated into $10 \mathrm{ml}$ yeast extract peptone dextrose (YPD) liquid medium and incubated on a shaking platform overnight $(200 \mathrm{rpm})$ at $30^{\circ} \mathrm{C}$. When the optical density at a wavelength of $600 \mathrm{~nm}(\mathrm{OD} 600)$ was 1.5 , the cultures were centrifuged at $3,000 \mathrm{x}$ g for $5 \mathrm{~min}$ in $4^{\circ} \mathrm{C}$. Subsequently, the pellet was resuspended using $300 \mathrm{ml}$ sterile water. After centrifugation, the supernatant was discarded and $20 \mathrm{ml}$ cold $1 \mathrm{M}$ sorbitol was used to resuspend the cells. Following this, the cells were subpackaged and stored at $-80^{\circ} \mathrm{C}$ until use.

Electroporation method. Electric rotor and lid (Gene Pulser Xcell $^{\mathrm{TM}}$; Bio-Rad Laboratories, Inc., Hercules, CA, USA) were irradiated in ultraviolet light overnight and the next day were placed in a $-20^{\circ} \mathrm{C}$ pre-cooling refrigerator. A total of $80 \mu 1$ of competent cells were mixed with $20 \mu \mathrm{g}$ plasmid, placed into a pre-chilled $0.2-\mathrm{cm}$ cuvette and then incubated on ice for $5 \mathrm{~min}$. An electric shock $(1.5 \mathrm{KV}, 25 \mu \mathrm{F}, 200 \Omega)$ was then applied using the Electric rotor and lid (Gene Pulser Xcell ${ }^{\mathrm{TM}}$; Bio-Rad Laboratories, Inc.). Subsequently, $1 \mathrm{ml}$ sorbitol (1 M) was added into the cuvette. Using pipetting to mix gently, the mixture was transferred to a $2.0-\mathrm{ml}$ sterile centrifuge tube and incubated at $30^{\circ} \mathrm{C}$ for $2 \mathrm{~h}$. Following this, the transformant was centrifuged at $3,000 \mathrm{x} \mathrm{g}$ for $1 \mathrm{~min}$ at $4^{\circ} \mathrm{C}$. Subsequently, $200 \mu \mathrm{l}$ sorbitol 1 M (Xilong Chemical Co., Ltd., Chaoshan, China.) was used to resuspend the cells, which were spread onto a YPDS medium containing zeocin (100 and $500 \mu \mathrm{g} / \mathrm{ml})$. The cells were cultured at $28^{\circ} \mathrm{C}$ for $2-4$ days.

P. pastoris genome DNA isolation. Monoclonal P. pastoris transformants were placed into YPD liquid medium and cultured overnight at $28^{\circ} \mathrm{C}$. A total of $2 \mathrm{ml}$ bacteria was taken from the culture and centrifuged at $13,000 \times \mathrm{g}$ for $2 \mathrm{~min}$ at $4^{\circ} \mathrm{C}$. Subsequently, the supernatant was discarded and $1 \mathrm{ml}$ phosphate-buffered saline was used to suspend the precipitate. The tubes were centrifuged at $12,000 \mathrm{rpm}$ for $2 \mathrm{~min}$ at $4^{\circ} \mathrm{C}$ and the supernatant was discarded. This step was repeated once more. The precipitate was dissolved in $100 \mu \mathrm{l}$ TE and heated in boiling water for $10 \mathrm{~min}$. Subsequently, the sample was immersed in liquid nitrogen for $1 \mathrm{~min}$, heated again in boiling water for $10 \mathrm{~min}$ and centrifuged at $12,000 \mathrm{rpm}$ for $15 \mathrm{~min}$ at $4^{\circ} \mathrm{C}$. The supernatant was used as a polymerase chain reaction (PCR) template.

PCR detection. The PCR mixture was as follows: $5 \mu \mathrm{l} \mathrm{Taq}$ buffer (10X), $1 \mu \mathrm{l}$ dNTP mixture $(2.5 \mathrm{mM}), 1.0 \mu \mathrm{l}$ each primer 20 pmol (forward: 5'-CTACTATTGCCAGCATTGCTGC-3'; reverse: 5'-GGCAAATGGCATTCTGACATCCT-3'), $1.0 \mu \mathrm{l}$ Taq polymerase (Takara Bio, Inc.), $1.0 \mu 1$ genome DNA template and $5.0 \mu \mathrm{DDH}_{2} \mathrm{O}$, giving a total reaction volume of $36.0 \mu \mathrm{l}$. The thermal cycling conditions were as follows: $94^{\circ} \mathrm{C}$ for $3 \mathrm{~min}$, followed by 25 cycles of $94^{\circ} \mathrm{C}$ for $30 \mathrm{sec}, 55^{\circ} \mathrm{C}$ for $45 \mathrm{sec}$ and $72^{\circ} \mathrm{C}$ for $1 \mathrm{~min}$, then $72^{\circ} \mathrm{C}$ for $10 \mathrm{~min}$ and finally held at $4^{\circ} \mathrm{C}$. PCR (GeneAmp 9600 PCR system; PerkinElmer, Waltham, MA, USA) was performed. All experiments were performed in triplicate. PCR products were detected using $1 \%$ agarose gel.

Identification of $P$. pastoris recombinant protein expression. A total of five positive yeast transformants were selected, each single clone was placed into $25 \mathrm{ml}$ buffered glycerol-complex medium [Yeast extract powder $10 \mathrm{~g}$, peptone $20 \mathrm{~g}$ and $700 \mathrm{ml}$ water; this was stirred until completely dissolved and then subjected to high pressure sterilization. It was then cooled to room temperature, followed by the addition of sterile: 10X YNB $100 \mathrm{ml}, 1 \mathrm{M}$ potassium phosphate buffer (PPB) 
$100 \mathrm{ml}, 100 \mathrm{ml}$ 10X sglycerin and $2 \mathrm{ml} 500 \mathrm{X}$ biotin (Xilong Chemical Co., Ltd.] and placed on a shaking platform at $200 \mathrm{rpm}\left(28^{\circ} \mathrm{C}\right)$, until OD600 reached 2-6. Subsequently, the mixture was centrifuged at 4,000 x g for $4 \mathrm{~min}$ at room temperature and the cells were collected. The bacterial cells were resuspended in $25 \mathrm{ml}$ buffered methanol-complex medium (Yeast extract powder $10 \mathrm{~g}$, peptone $20 \mathrm{~g}$ and $700 \mathrm{ml}$ water; it was stirred until completely dissolved then subjected to high pressure sterilization. It was then cooled to room temperature, followed by the addition of sterile: $100 \mathrm{ml} \mathrm{10X} \mathrm{YNB,} 100 \mathrm{ml}$ 1M PPB, $100 \mathrm{ml}$ 10X absolute methanol and $2 \mathrm{ml} 500 \mathrm{X}$ biotin) and placed on a shaking platform at $200 \mathrm{rpm}\left(28^{\circ} \mathrm{C}\right)$ to induce expression for 4 days. Every $24 \mathrm{~h}$, additional methanol was added at a $1 \%$ final concentration for further induction. Following this, $1 \mathrm{ml}$ medium was taken and placed into a 2.0-ml centrifuge tube and centrifuged at 13,000 x g for $5 \mathrm{~min}$ at $4^{\circ} \mathrm{C}$. Subsequently, electric loading buffer (Beijing Sunpu Biochemical Technology Co., Ltd., Beijing, China) was added for sample preparation. Western blotting was used to detect the target protein expression in cell supernatants and bacteria.

In vivo desaturase activity analysis. The induced culture of the transformation in the BMMY medium is the same as the aforementioned method, 1\% NP40, 0.5\% methanol and a final concentration of $100 \mu \mathrm{M}$ substrate arachidonic acid (ARA; Sigma-Aldrich; Merck KGaA) was added to the medium. Cell pellets were collected by centrifugation at $15,000 \mathrm{x} \mathrm{g}$ and $4^{\circ} \mathrm{C}$ for $15 \mathrm{~min}$ and stored at $-80^{\circ} \mathrm{C}$ for fatty acid analysis.

In vitro desaturase activity analysis. After expansion of the bacterial culture expressing $\Delta-17 \mathrm{FL}$, the medium was collected using purification. The medium was precipitated with ammonium sulfate and re-dissolved with $30 \mathrm{ml}$ of $20 \mathrm{mM}$ Phosphate Buffer, pH 7.2, and then Strong cation exchange medium (SP) Sepharose Fast Flow column (GE Healthcare, Chicago, IL, USA) was used for purification. $20 \mathrm{ml}$ purified protein was added to $200 \mathrm{ml}$ yeast cell homogenate. Yeast cells were lysed on ice for $30 \mathrm{~min}$ by adding lysis buffer $(20 \mathrm{mM}$ Tris- $\mathrm{HCl}$, pH 7.9, $500 \mathrm{mM} \mathrm{NaCl}, 10 \%$ glycerol, $1 \mathrm{mM}$ EDTA and 1\% NP40; Sigma-Aldrich; Merck KGaA), and a high pressure cell crusher (AH-1500; ATS Engineering Inc., Brampton, ON, Canada) was used to prepare the bacteria, the whole process operates on an ice bath. The enzyme reactions were performed at $28^{\circ} \mathrm{C}$ for $3 \mathrm{~h}$ with agitation $(250 \mathrm{rpm})$, and the assay mixture $(220 \mathrm{ml})$ was stored at $-80^{\circ} \mathrm{C}$ for fatty acid analysis.

Extraction of fatty acid and methyl esterification. The transformant cells were flash frozen and ground into powder in liquid nitrogen with a mortar. A total of $200 \mathrm{mg}$ powder was placed into a $10-\mathrm{ml}$ centrifuge tube, $3 \mathrm{ml}$ of chloroform-methanol $(\mathrm{v} / \mathrm{v}=2: 1)$ was added and the tube was vortexed for $30 \mathrm{~min}$. Then $1 \mathrm{ml}$ distilled water was added and mixed. Tubes were centrifuged at $4,000 \mathrm{xg}$ for $10 \mathrm{~min}$ in $4^{\circ} \mathrm{C}$, leaving the organic phase. The oil phase of nitrogen was added with $1 \mathrm{ml}$ acetyl chloride-methanol and vortexed for $3 \mathrm{~min}$. After incubated in a water bath at $92^{\circ} \mathrm{C}$ for $30 \mathrm{~min}, 2 \mathrm{ml}$ cold water and $400 \mu \mathrm{l}$-hexane (Xilong Chemical Co., Ltd.) were added, vortexed for $1 \mathrm{~min}$ and centrifuged at 5,500 $\mathrm{x} \mathrm{g}$ for $5 \mathrm{~min}$ at $4^{\circ} \mathrm{C}$. Subsequently, the upper organic phase was transferred into $1.5-\mathrm{ml}$ vials for gas chromatographic analysis.
Gas chromatography analysis. An Agilent 6890A gas chromatograph with a flame ionization detector and a column of HP-5 fused silica (length, $30 \mathrm{~m}$; inner diameter, $0.32 \mathrm{~mm}$; Agilent Technologies, Inc., Santa Clara, CA, USA) was used for analysis. The inlet and detector temperatures were both $250^{\circ} \mathrm{C}$. The high-purity carrier gas used was $\mathrm{He}$, with a flow rate of $7.5 \mathrm{ml} / \mathrm{min} . \mathrm{H}_{2}$ gas flow rate was $30 \mathrm{ml} / \mathrm{min}$, air flow rate was $400 \mathrm{ml} / \mathrm{min}$ and makeup was $20 \mathrm{ml} / \mathrm{min}$. The injection volume was $1 \mu$ l, using the split mode, and the split ratio was 20:1. By comparison with standard fatty acid (Sigma-Aldrich; Merck KGaA, Darmstadt, Germany) retention time to identify each fatty acid component, a calculated percentage area of each fatty acid was used to calculate component of normalization. Substrate conversion efficiency for $\omega-3$ desaturase is calculated as follows: $\mathrm{C}_{\text {product }} / \mathrm{C}_{\text {substrate }}$. $\mathrm{C}_{\text {product }}=\omega-3$ fatty acid [Eicosapentaenoic Acid $(\mathrm{EPA})+$ Docosapentenoic acid (DPA) ], represents the transformation product of the enzyme; $\mathrm{C}_{\text {substrate }}=\omega-6$ fatty acid (ARA), represents the transformation substrate of the enzyme.

Western blotting. Protein expression levels of phosphorylated (p)-glycogen synthase kinase (GSK)-3 $\beta$, GSK-3 $\beta, \beta$-catenin, p-protein kinase B (Akt) and Akt were determined in HepG2 cells from American Type Culture Collection (Manassas, VA, USA). The cell lysates were obtained using lysis buffer (50 mM Tris-Cl, pH 7.4; 1\% NP-40; 150 mM NaCl; $1 \mathrm{mM}$ EDTA; and, $0.5 \%$ sodium deoxycholate; all BD Biosciences) containing $1 \%$ protease inhibitors. Following centrifugation at $15,000 \mathrm{xg}$ for $10 \mathrm{~min}$ at $4^{\circ} \mathrm{C}$, the supernatant was collected. The protein concentration was detected using a bicinchoninic acid kit (Thermo Fisher Scientific, Inc.). Protein $(30 \mu \mathrm{g})$ from the vector and the treated group ( $\Delta 17$ overexpression) was separated on $10 \%$ SDS-PAGE and transferred onto nitrocellulose membranes. The $\Delta 17$ overexpression was the only group assessed because when the expression of target genes was identified by SDS-PAGE, $\triangle 17 \mathrm{FL}$ exhibited a clear expression, while the $\Delta 17 \mathrm{NT}$ exhibited no obvious band. After blocking the membranes with $5 \%$ no fat milk in Tris-buffered saline containing 0.1\% Tween-20 (TBST) for $1 \mathrm{~h}$ at room temperature, the membranes were incubated with the primary indicated antibodies Phosphorylation-GSK-3 $\beta$ (catalogue no. sc-135653; $1: 1,000), \beta$-catenin (catalogue no. sc-419477; 1:1,000), caspase-3 (catalogue no. sc-271028; 1:1,000), caspase-9 (catalogue no. sc-17784; 1:500; all Santa Cruz Biotechnology, Inc., Dallas, TX, USA) and anti- $\beta$-actin (catalogue no. 612656; 1:2,000; BD Biosciences, Franklin Lakes, NJ, USA) at $4^{\circ} \mathrm{C}$ overnight. Subsequently, membranes were washed five times for $5 \mathrm{~min}$ with TBST, incubated with horseradish peroxidase-conjugated immunoglobulin $\mathrm{G}$ goat anti-mouse IgG-HRP, (catalogue no. sc-2005; 1:3,000) goat and anti-rabbit IgG-HRP, (catalogue no. sc-2004; 1:3,000; both Santa Cruz Biotechnology, Inc.) at room temperature for $1 \mathrm{~h}$ and washed again five times for $5 \mathrm{~min}$ with TBST. The membranes were visualized using an enhanced chemiluminescence system (Sigma Aldrich; Merck KGaA), quantified using Image J version 2.1.4.7 (National Institutes of Health, Bethesda, MD, USA). $\beta$-actin was used as an internal control.

Cell viability assay. MTT assay was used to evaluate cell viability in vitro. Briefly, $2 \times 10^{3}$ HepG2 cells were seeded into 

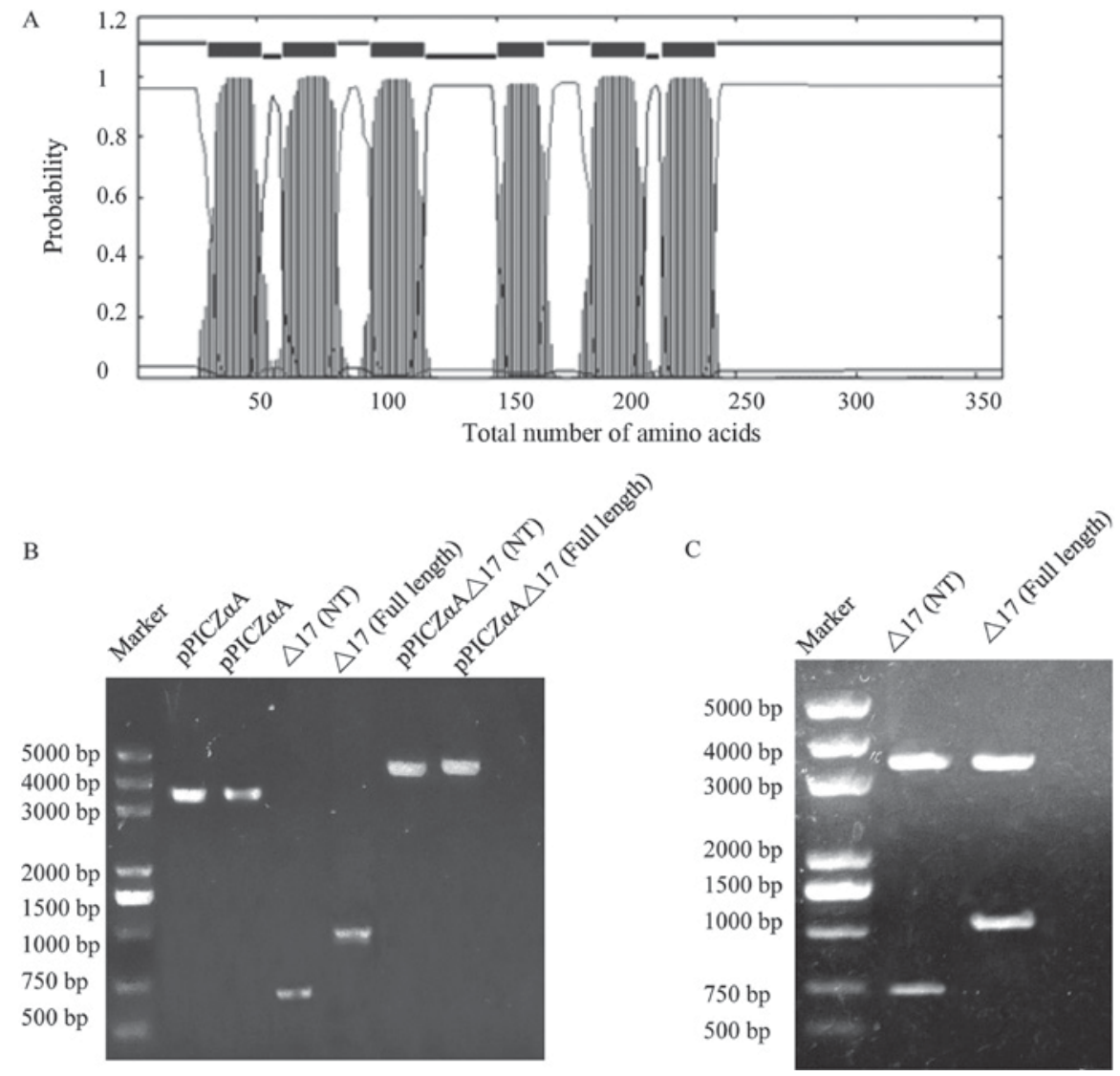

Figure 1. Cloning of full length or NT $\Delta-17$ ( $\omega-3)$ fatty acid desaturase. (A) The prediction of $\Delta-17$ ( $\omega-3)$ fatty acid desaturase transmembrane domain using TMpred (http://www.ch.embnet.org/software/TMPRED_form.html). (B) pPICZ $\alpha$ A and $\Delta$-17 (full length) or $\Delta-17$ (NT) were generated using the pPICZ $\alpha$ A expression vector and both digested with XhoI and NotI, and connected using T4 DNA ligase. (C) The relative plasmids were digested using the restriction enzyme $X b a \mathrm{I}$ and $X h o I$. NT, without transmembrane domain.

a 96-well plate for each group [Vector and $\Delta 17$ (NT) group]. The relative cells were incubated for $1,2,3$ and 4 days at $37^{\circ} \mathrm{C}$, MTT in PBS $(5 \mu \mathrm{g} / \mu \mathrm{l})$ was added to each well and incubated for $4 \mathrm{~h}$ at $37^{\circ} \mathrm{C}$. Following removal of the supernatant, $150 \mu \mathrm{l}$ dimethyl sulfoxide (Sigma-Aldrich; Merck KGaA) was added to each well. The absorbance value was measured at $490 \mathrm{~nm}$. Each experiment was performed in triplicate.

DNA fragmentation analysis. Apoptosis was detected and quantified by the Cell Death Detection ELISA PLUS kit (Roche Diagnostics, Ltd., Burgess Hill, UK), following the manufacturer's instructions. All experiments were performed in triplicate, independently. A DNA fragmentation terminal deoxynucleotidyl transferase dUTP nick end labeling assay was performed as follows: briefly, 50,000 cells were seeded with a regular DMEM medium at $37^{\circ} \mathrm{C}$ with $5 \% \mathrm{CO}_{2}$ and cultured under they reached $70-80 \%$ confluence. Next, cells were washed twice for 5 min with PBS and moved to DMEM without serum. At $0,24,48$ and $72 \mathrm{~h}$, pool DNA was extracted in a total of $400 \mu 1$ extraction buffer $(10 \mathrm{mM}$ Tris and $5 \mathrm{mM}$ EDTA). DNA fragmentation was calculated by the fold change, as compared with the vector and normalized with corresponding MTT results from identical culture conditions. The samples were analyzed by western blot analysis as described using caspase-3 (catalogue no. sc-271028; 1:1,000), caspase-9 (catalogue no. sc-17784; $1: 500$ ) and anti- $\beta$-actin (catalogue no. $612656 ; 1: 2,000)$.
Statistical analysis. Statistical analyses were performed using SPSS v. 11.0 software (SPSS, Inc., Chicago, IL, USA). The results were expressed as the mean \pm standard deviation. Differences between the groups were analyzed by one-way analysis of variance or a t-test followed by post-hoc test (Dunnett's test). $\mathrm{P}<0.05$ was considered to indicate a statistically significant difference.

\section{Results}

Cloning of full length or without transmembrane domain $\Delta-17$ $(\omega-3)$ fatty acid desaturase. As predicted using the TMHMM, the secondary structure of $\Delta-17$ Fatty acid desaturase had six transmembrane domains; the positions were from 30-52, 61-83, 98-120, 151-170, 190-212 and 219-241 nt (Fig. 1A). The $\Delta-17$ desaturase full length $(\Delta-17 \mathrm{FL})$ and $\Delta-17$ without transmembrane domain $(\Delta-17 \mathrm{NT})$ were synthesized with the potential restriction digestion position XhoI and NotI. The expression vector, pPICZ $\alpha$ A, was digested with XhoI and NotI. T4 DNA ligase was used to connect the pPICZ $\alpha \mathrm{A}$ and $\Delta-17$ (FL) or $\Delta-17$ (NT) to obtain the recombinant plasmid, the details are demonstrated in Fig. 1B. Furthermore, the relative plasmid was digested using the restriction enzyme $\mathrm{Xba \textrm {I }}$ and $\mathrm{XhoI}$ to measure whether the plasmid was orientated correctly. As demonstrated in Fig. 1C, the target gene was inserted into the vector correctly in the recombinant plasmids, and digestion was successful. 

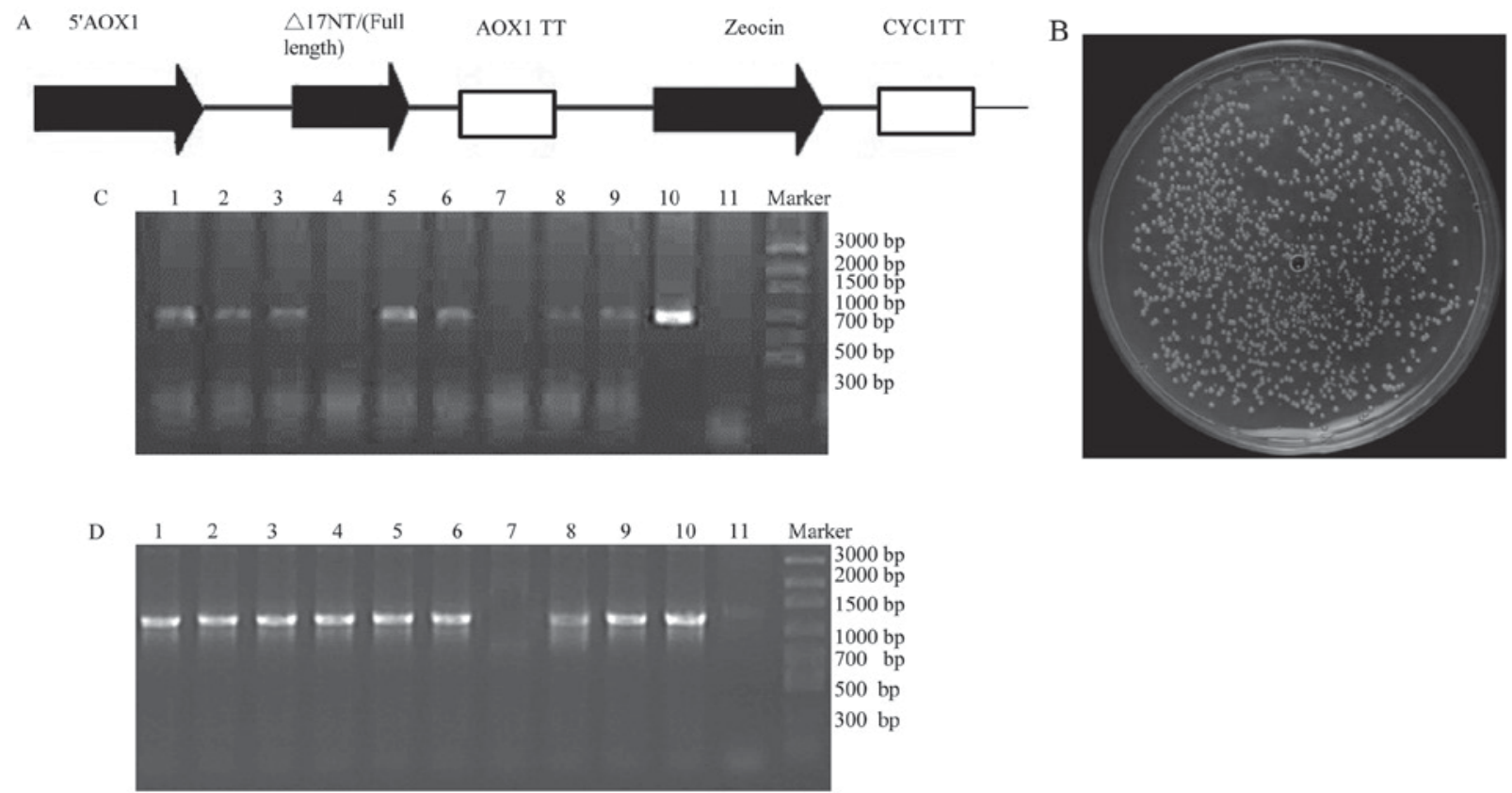

Figure 2. Expression and optimization conversion efficiency of $\Delta-17 \mathrm{NT}$ or $\Delta-17$ full length. (A) The linearization working model of pPICZ $\alpha$ A, $\Delta-17 \mathrm{NT}$ or $\Delta$-17 full length. (B) Preparation of Pichia pastoris competent cells. Polymerase chain reaction was used to detect the fragment of (C) $\Delta$-17NT and (D) $\Delta$-17 full length transfected into P. pastoris. NT, without transmembrane domain. Lanes 1-9: X-33/pPICZ $\alpha \mathrm{A}-\Delta-17 \mathrm{NT}$ ( $\Delta-17 \mathrm{FL}$ ) transformants; Lane 10: Vector pPICZ $\alpha A-\Delta-17 \mathrm{NT}(\Delta-17 \mathrm{FL})$ as positive control; Lane 11: X-33 as negative control. AOX1, alcohol oxidase 1; CYC1, cytochrome c1.

Expression and optimization conversion efficiency of $\Delta-17 N T$ or $\Delta-17 F L$. The recombinant plasmids, $\Delta-17 \mathrm{NT}$ and $\Delta-17 \mathrm{FL}$, and expression vector, pPICZ $\alpha \mathrm{A}$, were linearized using the restriction enzyme SalI. The working model is demonstrated in Fig. 2A. Preparation of P. pastoris competent cells is demonstrated in Fig. 2B, using an electroporation method to induce recombinant yeast transformants containing $\Delta-17 \mathrm{NT}$ or $\Delta-17 \mathrm{FL}$ fragments. PCR was used to identify the genome of the transformants, as demonstrated in Fig. 2C and D. The fragments of $\Delta-17 \mathrm{NT}$ or $\Delta-17 \mathrm{FL}$ were correctly inserted into $P$. pastoris, as detected by PCR with specific primers. The protein expression of $\Delta-17 \mathrm{FL}$ was measured by SDS-PAGE, as indicated in Fig. 3A. A positive control was used to confirm the efficiency, while conditioned medium of pPICZ $\alpha A-\Delta-17 \mathrm{FL}$ without induction was used as a negative control. Similarly, the protein expression of $\Delta-17 N T$ is demonstrated in Fig. 3B.

Effect of $\triangle-17 N T$ or $\triangle-17 F L$ expression on P. pastoris fatty acid composition. In order to understand the effect of $\Delta-17 \mathrm{NT}$ or $\Delta-17 \mathrm{FL}$ expression on P. pastoris fatty acid composition, the PCR positive transformants with empty vector or recombinants containing $\Delta-17 \mathrm{NT}$ or $\Delta-17 \mathrm{FL}$ were transferred to $3-\mathrm{ml}$ tubes containing liquid medium. $1 \%$ NP40, $0.5 \%$ methanol and a final concentration of $100 \mu \mathrm{M}$ substrate ARA was added to the medium. The blank control of each group was used without adding ARA (Arachidonic acid) as substrate. All samples were added to methanol for induction every 24 , and $96 \mathrm{~h}$ after fermentation, the cultured cells were collected by centrifugation and used for extraction of fatty acid and methyl esterification, followed by gas chromatography analysis.

As demonstrated in Fig. 4A, 37 kinds of standard fatty acid methyl products were analyzed using gas chromatography
A

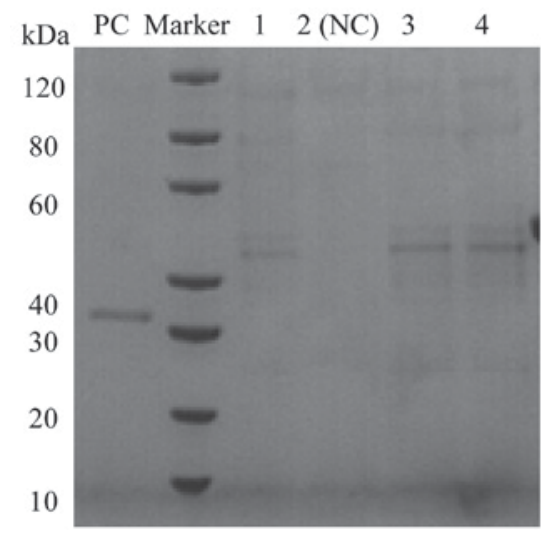

B

Figure 3. (A) Following culture in conditioned medium of pPICZ $\alpha \mathrm{A}-\Delta-17 \mathrm{FL}$ with induction for $96 \mathrm{~h}$ at $28^{\circ} \mathrm{C}$, the expression of $\Delta-17 \mathrm{FL}$ using different Pichia pastoris monoclones was measured by SDS-PAGE. BCA was used as a PC and conditioned medium of pPICZ $\alpha \mathrm{A}-\Delta-17 \mathrm{FL}$ without induction was used as a NC. Lane 1, 3 and 4 demonstrated pPICZ $\alpha$ A- $\Delta-17 F L$ induction. (B) Similarly, the expression of $\Delta-17 \mathrm{NT}$ was measured using SDS-PAGE. FL, full length; NT, without transmembrane domain; PC, positive control; NC, negative control; BCA, bicinchoninic acid.

analysis. Transfection with empty vector in yeast fermentation broth was conducted to analyze fatty acid composition, with or without added ARA (Fig. 4B). Fig. 5A indicates the gas chromatography results after transfection with $\Delta$-17FL gene in yeast fermentation broth to analyze fatty acid composition. Fig. 5B demonstrated the gas chromatography results after transfection with the $\Delta$-17NT gene in yeast fermentation broth to analyze fatty acid composition, by comparison with retention time in standard fatty acid to identify each fatty acid component, to calculate each fatty acid component 
A

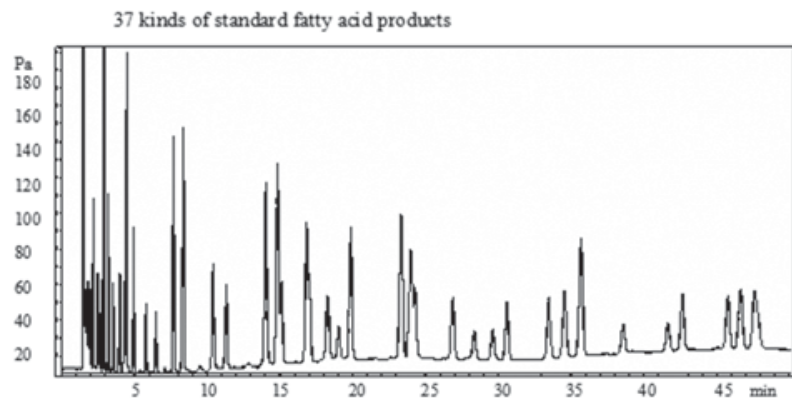

B

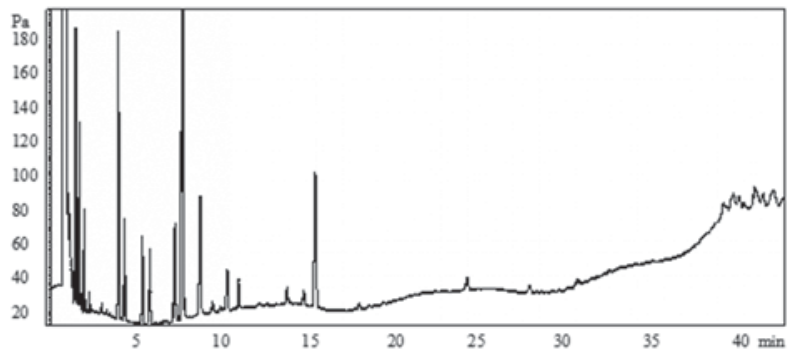

C

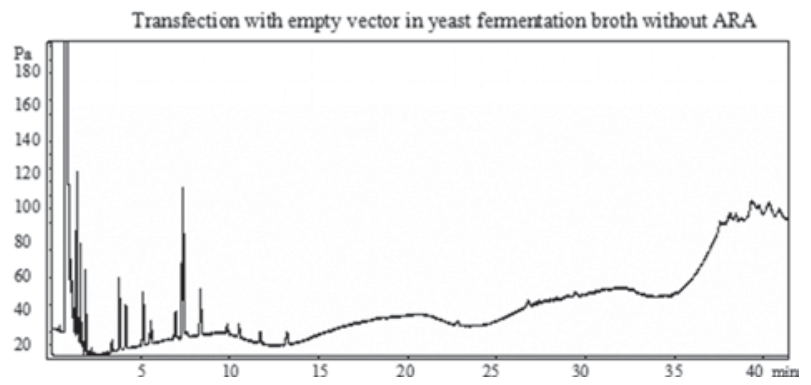

Figure 4. Effect of $\Delta-17$ without transmembrane domain or full length $\Delta-17$ on Pichia pastoris fatty acid composition. (A) Gas chromatography analysis was used to analyze 37 kinds of standard fatty acid products. (B and C) Gas chromatography analysis was used to analyze fatty acid composition after transfection with empty vector in yeast fermentation broth and ARA was either (B) added as a substrate or (C) not added. ARA, arachidonic acid.

using the area normalization method. It was demonstrated in Figs. 4B and 5 that, when ARA was added as a substrate to the induction medium, the results were markedly different in the $\Delta-17 \mathrm{FL}$ group compared with the empty vector group and the $\Delta$-17NT transfection group, in the transfection group, the substrate ARA was decreased and the product EPA, DPA were increased. This indicates that the target gene, $\Delta-17 \mathrm{FL}$, may serve a normal function of the $\omega 3$ Fatty acid desaturase, converting $\omega 6$ Fatty acid to $\omega 3$ Fatty acid. However, the result was similar in empty vector group and the $\Delta-17 \mathrm{NT}$ transfection group. However, in the no-ARA groups, there was no obvious difference between the empty vector, the $\Delta-17 \mathrm{FL}$ or the $\Delta-17 \mathrm{NT}$ transfection groups.

Purification and activity analysis of $\Delta-17$ fatty acid desaturase. SDS-PAGE was used to detect the dissolution and purification of $\Delta-17 \mathrm{FL}$, as demonstrated in Fig. $6 \mathrm{~A}$ and $\mathrm{B}$. Also, compared with the retention time in 37 standard fatty acids to identify each fatty acid component, after purification and after ARA had been added as a substrate, under the action of $\Delta$-17FL, ARA/(EPA + DPA) from a ratio of 8.18:1 (empty vector group; Fig. 6C) was reduced to $3.60: 1$ (yeast transfected with $\Delta$-17FL group). The results were markedly different compared with the empty vector group (Fig. 7A). While under the influence of
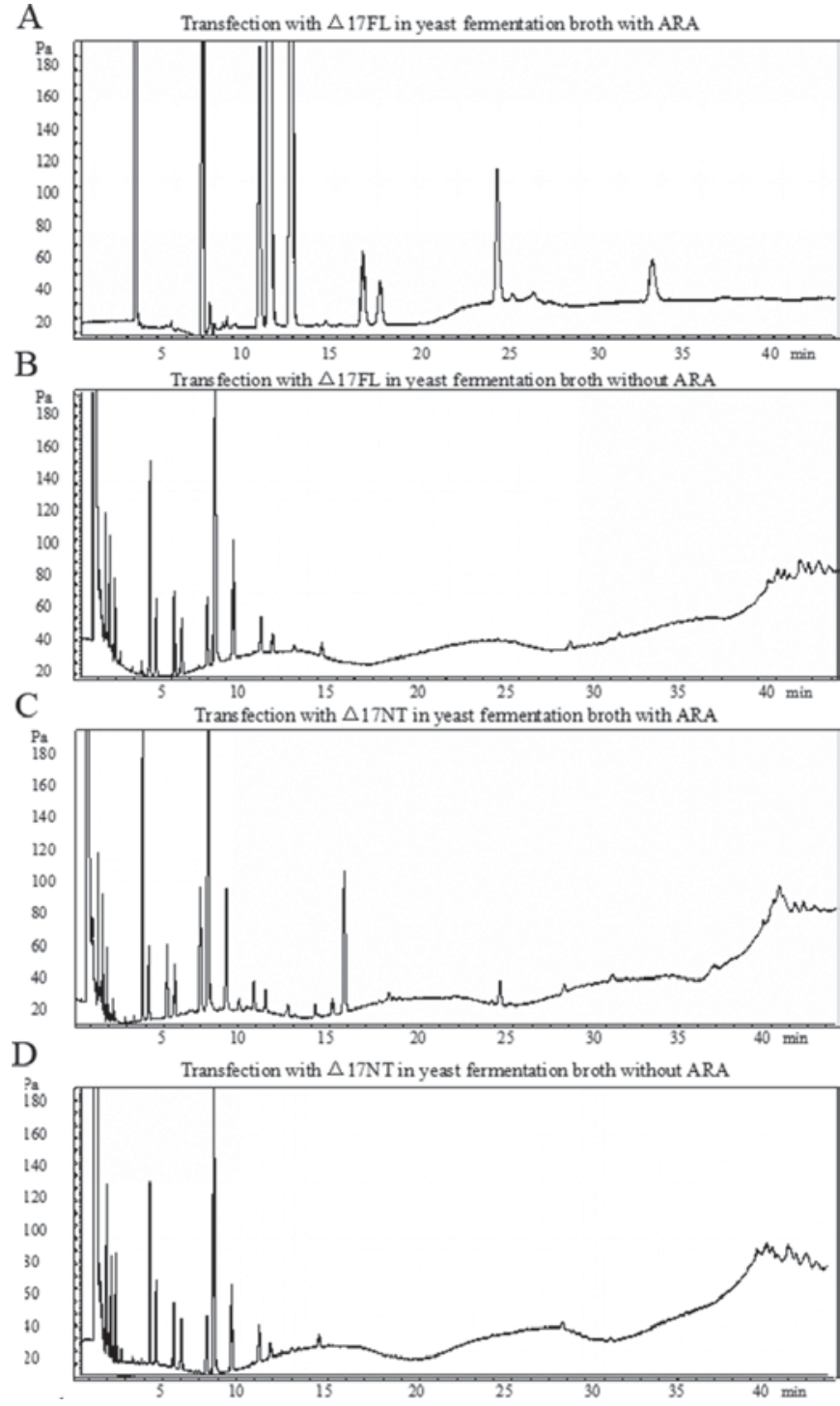

Figure 5. (A and B) Gas chromatography analysis was used to analyze fatty acid composition after transfection with $\Delta-17 \mathrm{FL}$ in yeast fermentation broth, ARA was either (A) added as a substrate or (B) not added. (C and D) Gas chromatography analysis was used to analyze fatty acid composition after transfection with $\Delta$-17NT in yeast fermentation broth, ARA was either (C) added as a substrate or (D) not added. FL, full length; NT, without transmembrane domain; ARA, arachidonic acid.

$\Delta-17 \mathrm{NT}, \mathrm{ARA} /(\mathrm{EPA}+\mathrm{DPA})$ from a ratio of 8.18:1 (empty vector) was reduced to $4.11: 1$ ( $\Delta$-17NT group). The results were markedly different compared with the empty vector group (Fig. 7B). As for the role of the purified enzyme $\Delta-17 \mathrm{FL}$ (Fig. 7B), ARA/(EPA + DPA) from a ratio of 8.18:1 (empty vector group) was reduced to $3.34: 1$ ( $\Delta-17 \mathrm{FL}$ purification group), the results were markedly different compared with the empty vector group (Fig. 8). However, in the $\Delta-17 \mathrm{NT}$ group, the enzyme activity was lower compared with the $\Delta-17 \mathrm{FL}$ purification group.

Expression of pPICZ $\alpha A-\Delta-17 N T$ decreases cell viability and increases apoptosis in vitro. To determine whether $\Delta-17 \mathrm{NT}$ inhibits cell viability in vitro, MTT assays were performed in HepG2 cells cultured with $\Delta$-17NT for different time periods at $0,24,48,72$ and $96 \mathrm{~h}$. As demonstrated in Fig. 9A, expression of pPICZ $\alpha \mathrm{A}-\Delta-17 \mathrm{NT}$ significantly inhibited cell viability compared with cells that were transfected with control vector at 

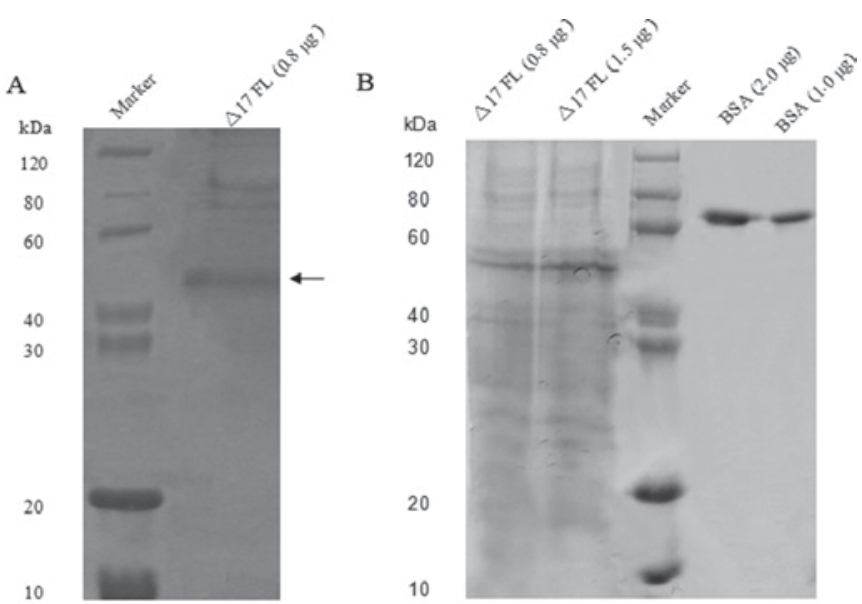

$\mathrm{C}$
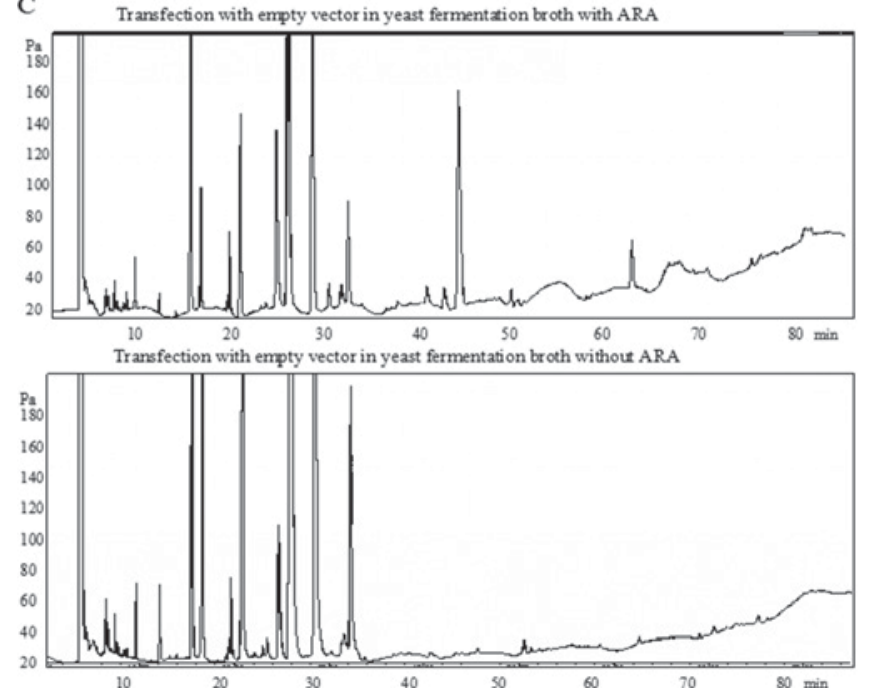

Figure 6. Purification and activity analysis of $\Delta-17$ fatty acid desaturase. (A) SDS-PAGE was used to detect the dissolution of $\Delta-17$ after precipitation with ammonium sulfate. (B) The purification of $\Delta-17 \mathrm{FL}$ was detected using SDS-PAGE after dialysis with $3.5 \mathrm{kDa}$ dialysis bag and SP Sepharose FF column. BSA was used to confirm the expression level. (C) Gas chromatography analysis was used to analyze fatty acid composition after transfection with empty vector in yeast fermentation broth, ARA was added as a substrate (upper panel) or not added (lower panel). FL, full length; ARA, arachidonic acid; SP, Sepharose; FF, Fast Flow.

72 and $96 \mathrm{~h}(\mathrm{P}<0.001)$. To evaluate whether pPICZ $\alpha \mathrm{A}-\Delta-17 \mathrm{NT}$ had a role in programmed cell death, a DNA fragmentation terminal deoxynucleotidyl transferase dUTP nick end labeling assay was performed in HepG2 cells. The apoptosis of HepG2 cells was significantly enhanced in the pPICZ $\alpha A-\Delta-17 \mathrm{NT}$ expression groups at 48 and $72 \mathrm{~h}$ compared with the control vector $(\mathrm{P}<0.05$; Fig. 9B). To further investigate the mechanism of $\Delta-17 \mathrm{NT}$ expression on the inhibition of tumor cell proliferation, proteins involved in cell proliferation were examined, including p-GSK-3 $\beta$ and $\beta$-catenin, (Fig. 9C). It was demonstrated that $\Delta-17 \mathrm{NT}$ expression markedly reduced the expression level of p-GSK-3 $\beta$ and $\beta$-catenin compared with the control vector, which indicated that $\Delta-17 \mathrm{NT}$ inhibited cell proliferation. As for cell apoptosis, the cleavage of caspase- 9 and caspase-3 was markedly enhanced in cells transfected with $\Delta$-17NT compared with cells transfected with the control vector (Fig. 9D). The above results indicated that expression of $\Delta$-17NT induced caspase-3-mediated cell apoptosis and inhibited cell viability and proliferation.
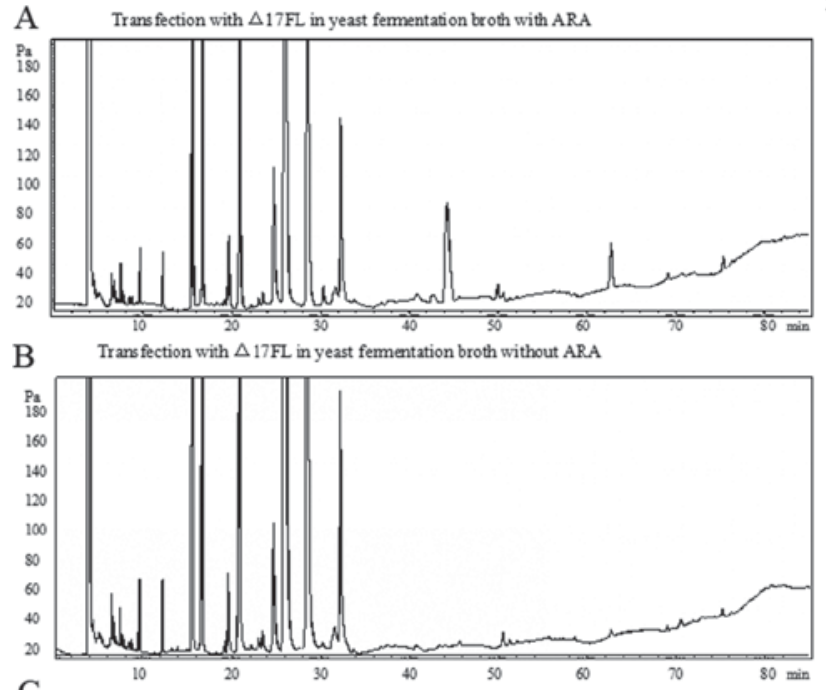

$\mathrm{C}$
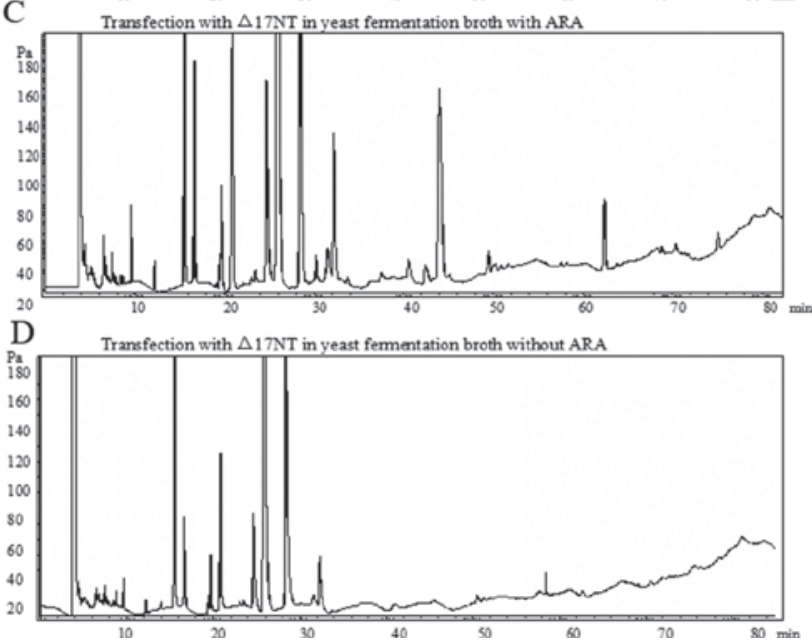

Figure 7. (A and B) Gas chromatography analysis was used to analyze fatty acid composition after transfection with $\Delta-17 \mathrm{FL}$ in yeast fermentation broth, ARA was either (A) added as a substrate or (B) not added. (C and D) Gas chromatography analysis was used to analyze fatty acid composition after the transfection with $\Delta-17 \mathrm{NT}$ in yeast fermentation broth, ARA was either (C) added as a substrate or (D) not added. FL, full length; NT, without transmembrane domain; ARA, arachidonic acid.
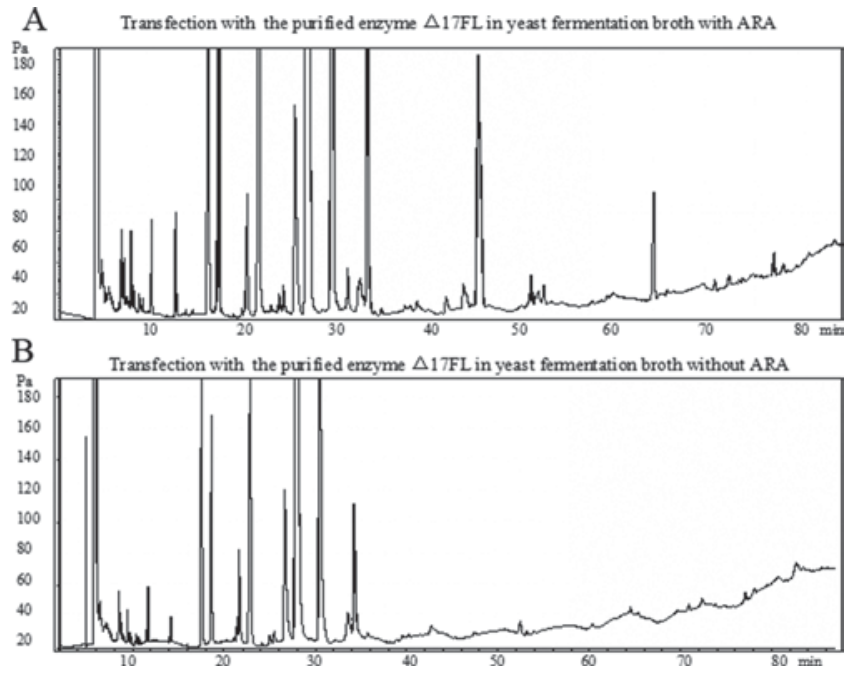

Figure 8 . Gas chromatography analysis was used to analyze fatty acid composition after transfection with purified enzyme $\Delta$-17FL in yeast fermentation broth, ARA was either (A) added as a substrate or (B) not added. FL, full length; ARA, arachidonic acid. 


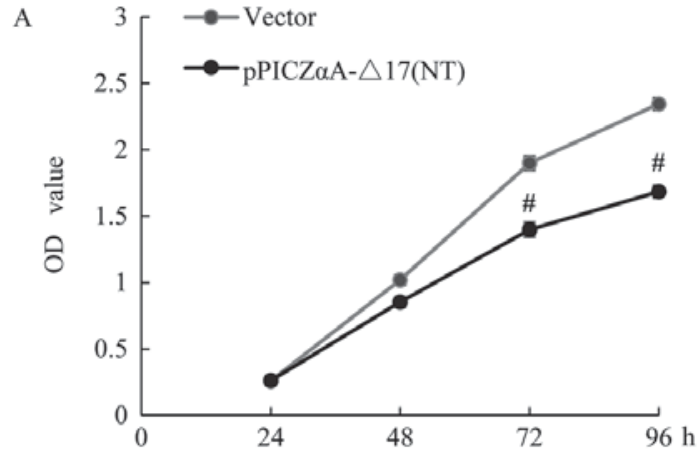

B

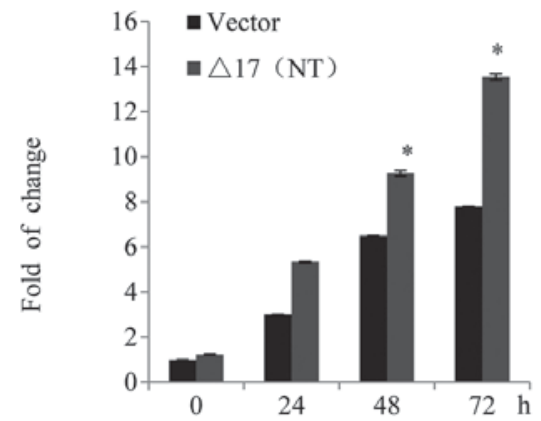

C
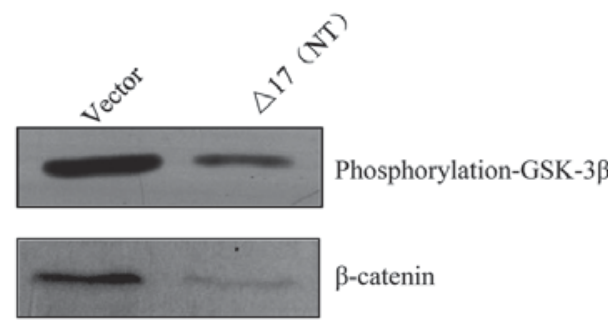

D

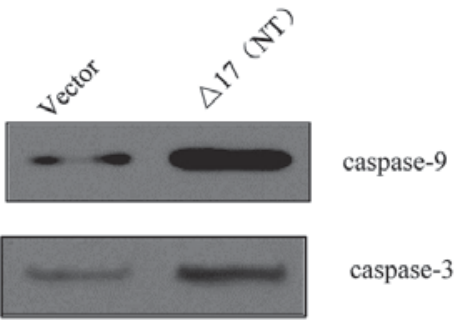

Figure 9. Effect of pPICZ $\alpha \mathrm{A}-\Delta-17 \mathrm{NT}$ expression on cell viability and apoptosis in vitro. (A) MTT assay was used to measure HepG2 cell viability, equal numbers of cells were transfected with pPICZ $\alpha \mathrm{A}-\Delta-17 \mathrm{NT}$ or vector and cultured. MTT assay was performed every $24 \mathrm{~h}$. Data are presented as the mean \pm standard deviation. (B) DNA fragmentation terminal deoxynucleotidyl transferase dUTP nick end labeling assay was performed in HepG2 cells transfected with pPICZ $\alpha \mathrm{A}-\Delta-17 \mathrm{NT}$ or vector. The apoptosis level was measured every $24 \mathrm{~h}$. Data are presented as the mean + standard deviation. The fold change is relative to vector at $0 \mathrm{~h}$. (C) The level of GSK-3 $\beta$ phosphorylation and $\beta$-catenin expression was demonstrated in HepG2 cells transfected with pPICZ $\alpha \mathrm{A}-\Delta-17 \mathrm{NT}$ or vector. (D) The level of cleavage of caspase- 9 and caspase-3 was demonstrated in HepG2 cells transfected with pPICZ $\alpha A-\Delta-17$ NT or vector. ${ }^{~} \mathrm{P}<0.001$ and ${ }^{*} \mathrm{P}<0.05$ vs. vector at the same time point. NT, without transmembrane domain; vector, control vector; OD, optical density.

\section{Discussion}

Three new $\omega-3$ desaturases that convert $\omega-6$ fatty acids to the $\omega-3$ unsaturated form have been identified and isolated, all of which belong to the type II desaturase that introduce a double bond near the methyl end of an unsaturated fatty acid $(12,13)$.
The transmembrane domain is a strong hydrophobic transmembrane region, and exhibits good hydrophobicity within the membrane (14). There is no necessary association between the extracellular receptor function and transmembrane domain (15). Contrastingly, the interaction between highly hydrophobic peptides and important proteins within the host cell, such as the signal recognition particle complex, may lead to protein expression inhibition or protein precipitation (16-18). Therefore, in the present study, the function of full-length $\Delta-17$ and $\Delta-17$ without transmembrane domain was analyzed and compared. It was demonstrated that after the addition of ARA as a substrate, the effect of $\Delta-17 \mathrm{NT}$ or $\Delta-17 \mathrm{FL}$ expression on $P$. pastoris fatty acid composition was highly efficient for the transformation of ARA compared with the vector.

Previous studies have demonstrated that $\omega-3$ fatty acids may antagonize the stimulative roles of $\omega-6$ fatty acids in different types of carcinogenesis, such as lung cancer (19) and prostate cancer (20), to regulate tumor proliferation and metastasis. The present study revealed that in a hepatocellular carcinoma cell line, $\Delta-17 \mathrm{NT}$ also decreased cell viability and increased apoptosis in vitro, which further demonstrated the function of $\omega-3$ fatty acids in cancer progression $(21,22)$.

In conclusion, understanding the underlying mechanism of the function of $\Delta-17$ fatty acid desaturase with or without the transmembrane domain in HepG2 cells may contribute to the understanding of the contribution of fatty acid desaturases in tumor progression, which may serve as a therapeutic target in the future.

\section{References}

1. Amminger GP, Schäfer MR, Papageorgiou K, Klier CM, Cotton SM, Harrigan SM, Mackinnon A, McGorry PD and Berger GE: Long-chain omega-3 fatty acids for indicated prevention of psychotic disorders: A randomized, placebo-controlled trial. Arch Gen Psychiatry 67: 146-154, 2010.

2. Bézard J, Blond JP, Bernard A and Clouet P: The metabolism and availability of essential fatty acids in animal and human tissues. Reprod Nutr Dev 34: 539-568, 1994.

3. Driss F, Duranthon V, Darcet P and Henry O: Effects of dietary omega- 6 and omega-3 fatty acids on levels of long chain polyunsaturated fatty acids in erythrocytes. C R Seances Soc Biol Fil 185: 14-20, 1991 (In French).

4. Shanklin J and Cahoon EB: Desaturation and related modifications of fatty ACIDS1. Annu Rev Plant Physiol Plant Mol Biol 49: 611-641, 1998.

5. Ameur A, Enroth S, Johansson A, Zaboli G, Igl W, Johansson AC, Rivas MA, Daly MJ, Schmitz G, Hicks AA, et al: Genetic adaptation of fatty-acid metabolism: A human-specific haplotype increasing the biosynthesis of long-chain omega-3 and omega- 6 fatty acids. Am J Hum Genet 90: 809-820, 2012.

6. Sakuradani E, Kobayashi M, Ashikari T and Shimizu S: Identification of Delta12-fatty acid desaturase from arachidonic acid-producing mortierella fungus by heterologous expression in the yeast Saccharomyces cerevisiae and the fungus Aspergillus oryzae. Eur J Biochem 261: 812-820, 1999.

7. Muhlhausler BS, Cook-Johnson R, James M, Miljkovic D, Duthoit E and Gibson R: Opposing effects of omega-3 and omega- 6 long chain polyunsaturated fatty acids on the expression of lipogenic genes in omental and retroperitoneal adipose depots in the rat. J Nutr Metab 2010: pii: 927836, 2010.

8. Markus M, Husen B, Leenders F, Seedorf U, Jungblut PW, Hall PH and Adamski J: Peroxisomes contain an enzyme with 17 beta-estradiol dehydrogenase, fatty acid hydratase/dehydrogenase, and sterol carrier activity. Ann N Y Acad Sci 804: 691-693, 1996.

9. Carballeira NM, Montano N, Balaña-Fouce R and Prada CF: First total synthesis and antiprotozoal activity of (Z)-17-methyl-13-octadecenoic acid, a new marine fatty acid from the sponge Polymastia penicillus. Chem Phys Lipids 161: 38-43, 2009. 
10. Kim DH, Choe YS, Choi JY, Choi Y, Lee KH and Kim BT: 17-[4-(2-[18F]fluoroethyl)-1H-1,2,3-triazol-1-yl]-6-thia-heptadecanoic acid: A potential radiotracer for the evaluation of myocardial fatty acid metabolism. Bioconjug Chem 20: 1139-1145, 2009.

11. Xue X, Feng CY, Hixson SM, Johnstone K, Anderson DM Parrish CC and Rise ML: Characterization of the fatty acyl elongase (elovl) gene family, and hepatic elovl and delta-6 fatty acyl desaturase transcript expression and fatty acid responses to diets containing camelina oil in Atlantic cod (Gadus morhua). Comp Biochem Physiol B Biochem Mol Biol 175: 9-22, 2014.

12. Zhu G, Saleh AA, Bahwal SA, Wang K, Wang M, Wang D, Ge T and Sun J: Overexpression of four fatty acid synthase genes elevated the efficiency of long-chain polyunsaturated fatty acids biosynthesis in mammalian cells. Sheng Wu Gong Cheng Xue Bao 30: 1464-1472, 2014 (In Chinese).

13. Uttaro AD: Biosynthesis of polyunsaturated fatty acids in lower eukaryotes. IUBMB Life 58: 563-571, 2006.

14. Fink A, Sal-Man N, Gerber D and Shai Y: Transmembrane domains interactions within the membrane milieu: Principles, advances and challenges. Biochim Biophys Acta 1818: 974-983, 2012.

15. Lim ZL, Senger T and Vrinten P: Four amino acid residues influence the substrate chain-length and regioselectivity of Siganus canaliculatus $\Delta 4$ and $\Delta 5 / 6$ desaturases. Lipids 49: 357-367, 2014.

16. Kempf G, Wild K and Sinning I: Structure of the complete bacterial SRP Alu domain. Nucleic Acids Res 42: 12284-12294, 2014
17. Kuhn P, Weiche B, Sturm L, Sommer E, Drepper F, Warscheid B, Sourjik V and Koch HG: The bacterial SRP receptor, SecA and the ribosome use overlapping binding sites on the SecY translocon. Traffic 12: 563-578, 2011.

18. Braig D, Bär C, Thumfart JO and Koch HG: Two cooperating helices constitute the lipid-binding domain of the bacterial SRP receptor. J Mol Biol 390: 401-413, 2009.

19. Xia SH, Wang J and Kang JX: Decreased n-6/n-3 fatty acid ratio reduces the invasive potential of human lung cancer cells by downregulation of cell adhesion/invasion-related genes. Carcinogenesis 26: 779-784, 2005.

20. Lu Y, Nie D, Witt WT, Chen Q, Shen M, Xie H, Lai L, Dai Y and Zhang J: Expression of the fat-1 gene diminishes prostate cancer growth in vivo through enhancing apoptosis and inhibiting GSK-3 beta phosphorylation. Mol Cancer Ther 7: 3203-3211, 2008.

21. Li X, Ballantyne LL, Che X, Mewburn JD, Kang JX, Barkley RM, Murphy RC, Yu Y and Funk CD: Endogenously generated omega-3 fatty acids attenuate vascular inflammation and neointimal hyperplasia by interaction with free fatty acid receptor 4 in mice. J Am Heart Assoc 4: pii: e001856, 2015.

22. Jeong S, Jing K, Kim N, Shin S, Kim S, Song KS, Heo JY, Park JH, Seo KS, Han J, et al: Docosahexaenoic acid-induced apoptosis is mediated by activation of mitogen-activated protein kinases in human cancer cells. BMC Cancer 14: 481, 2014. 